\title{
Enhancing saltiness in emulsion based foods
}

\author{
Mita Lad ${ }^{1,2}$, Louise Hewson ${ }^{1}$ and Bettina Wolf ${ }^{1 *}$
}

\begin{abstract}
Background: The concept of enhancing saltiness perception in emulsions and a liquid food formulated with the emulsions (ambient vegetable soup) through increasing salt concentration in the continuous phase while retaining the fat content of the (aqueous continuous) product was evaluated. This was accomplished by increasing the droplet phase volume using duplex emulsion technology. Viscosity and droplet size distribution was measured. Saltiness evaluation was based on simple paired comparison testing (2-Alternate Forced Choice tests, BS ISO 5495:2007).

Results: Single and duplex emulsions and emulsion-based products had comparable mean oil droplet diameters (25 to $30 \mu \mathrm{m}$ ); however, viscosity of the duplex emulsion systems was considerably higher. Sensory assessment of saltiness of emulsion pairs (2AFC) indicated duplex technology enhanced saltiness perception compared to a single emulsion product at the same salt content $(6.3 \mathrm{~g} / 100 \mathrm{~g})$ in both simple emulsions and the formulated food product ( $P=0.0596$ and 0.0004 respectively) although assessors noted the increased viscosity of the duplex systems. The formulated food product also contained pea starch particles which may have aided product mixing with saliva and thus accelerated tastant transport to the taste buds. Lowering salt content in the duplex systems (to levels of aqueous phase salt concentration similar to the level in the single systems) resulted in duplex systems being perceived as less salty than the single system. It appears that the higher viscosity of the duplex systems could not be "overruled" by enhanced mixing through increased droplet phase volume at lowered salt content.

Conclusions: The results showed that salt reduction may be possible despite the added technology of duplex systems increasing the overall measured viscosity of the product. The changes in viscosity behavior impact mouthfeel, which may be exploitable in addition to the contribution towards salt reduction. With a view to applying this technology to real processed foods, it needs to be tested for the product in question but it should be considered as part of a salt reduction tool box.
\end{abstract}

Keywords: Salt, Health, Duplex emulsions, Microstructure, Fat

\section{Background}

Salt $(\mathrm{NaCl})$ has been traditionally used as a food preservative to reduce microbial growth, thereby preventing food spoilage. Salt also plays a crucial role in imparting saltiness to foods, and enhancing or masking flavors, as well as being essential for textural attributes of some products [1]. Reported intake of salt by adults in most Western countries has been estimated to be 9 to $12 \mathrm{~g}$ per day [2], which is much greater than the level currently recommended by the World Health Organization (WHO) of a maximum of $6 \mathrm{~g}$ per day [3]. The negative health consequences of high salt intake have been widely

\footnotetext{
* Correspondence: Bettina.Wolf@nottingham.ac.uk

${ }^{1}$ Food Sciences, Sutton Bonington Campus, The University of Nottingham, Loughborough LE12 5RD, UK

Full list of author information is available at the end of the article
}

reported. Of most concern is the direct link to the development of hypertension [4,5] which subsequently increases the chance of developing cardiovascular disease [6,7] and renal disease [8,9].

Excessive intake of salt through the Western diet has been attributed to the relatively large amounts of salt contained in prepared/pre-cooked foods. It has been estimated that over $75 \%$ of daily salt intake comes from processed foods [10]. Reduction of the overall amount of salt added to processed food is one possible strategy to reduce salt intake [11]. However, simply reducing the amount of salt added to foods not only represents technological difficulties and, in case of some foods, a safety risk, it inevitably means a compromise in product taste and flavor with negative impact on consumer acceptability. Despite these restraints, overall salt reduction

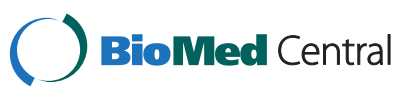


has been successfully applied to staple foodstuffs, such as bread, using gradual step-wise reduction [12]. This approach is time consuming, with levels being reduced slowly over several years. An alternative strategy is to use salts with an alternative cation, as it is the sodium causing the negative health impact. Replacement of $\mathrm{NaCl}$ with potassium chloride $(\mathrm{KCl})$ has had mixed results as $\mathrm{KCl}$ is often reported to be bitter and can produce a metallic aftertaste [13-15]. The presence of low levels of $\mathrm{NaCl}[16,17]$ and substances imparting umami taste [18], for example in savory soups [18-20], can mask this bitter taste, rendering low-level substitution of $\mathrm{NaCl}$ with $\mathrm{KCl}$ feasible. In [1], it has been reported that naturally brewed soy sauce can replace $\mathrm{NaCl}$ without lowering overall taste intensity or decreasing consumer acceptance. Generally, adding components such as arginine [21], lysine [11] or glutamate [22], which enhance the umami character of food, may raise saltiness perception and may be a suitable approach in certain food types. Another method to enhance saltiness perception includes the use of specific odor-taste interactions in the presence of expected flavors [23,24].

The approach adopted in this study on salt reduction was based on enhancing salt concentration in the continuous product phase and is applicable to aqueousbased foods. Food emulsions, with the droplets acting as inert filler particles excluding salt from the volume corresponding to the dispersed phase volume of the emulsion, were evaluated. This approach has been taken in the past; increase in saltiness perception from oil-inwater emulsions with increasing oil phase volume and constant total amount of salt has been reported $[25,26]$. It was also found that with increasing oil phase volume for emulsions of constant continuous phase salt concentration, salt perception declined as the presence of oil obstructed the salt from reaching the taste buds $[25,26]$. Recently, a corresponding approach using air bubbles as "tastant excluded fillers" in a water-based gel has been reported [27]. It was described as offering scope for the reduction of sodium chloride and sucrose. In this case, no effect of filler phase volume on taste perception in samples with constant continuous phase tastant concentration was found as air would simply escape leaving the tastant to reach the taste buds. There was, however, an impact on sample texture and appearance due to the presence of $40 \%$ volume fraction of air bubbles.

In the literature cited thus far, the salt was dissolved in the aqueous product phase corresponding to the continuous product phase, in which it was equally distributed. Strategies to enhance saltiness perception at equi-salt stimuli by creating localized concentration differences have also been explored. Formulation of products with salt gradients is less of a challenge for low moisture content foods, such as bread, as diffusion is restricted, and it has been successfully applied [28]. The magnitude of saltiness enhancement was shown to depend on the total salt content (highest for lowest level) and sensory contrast (increased with increasing heterogeneity). For liquid foods this approach can only be realized by encapsulating the stimulant and facilitating release during oral processing. Whereas design of suitable food microstructures remains a challenge, the hypothesis of increased taste perception by temporal changes of tastant concentration using pulsed delivery systems has been tested for sweetness [29] and saltiness perception [20,30,31]. With respect to saltiness perception, success has been shown to be mixed depending on the time scale of the experiment. Spiking salt concentration within a delivery period of $15 \mathrm{~s}$ had no effect on saltiness perception and overall saltiness perception depended on the overall delivered amount of salt [31]. A $30 \mathrm{~s}$ long delivery period on the other hand was shown to increase salt perception based on short and intense stimulus delivery periods [30].

Here we report the results of a study undertaken to assess salt reduction in a simple ambient vegetable soup. The product was based on emulsion technology and the fat content of the food product was retained constant through application of duplex emulsion technology. Thereby, we specifically refer to oil-in-water emulsions with an included water phase in the internal oil phase. Such duplex emulsions are known as water-in-oil-inwater emulsions, or in short, w/o/w. Based on [26], samples with higher dispersed phase volume were expected to be perceived as saltier when the overall salt concentration was kept constant, although the emulsion system evaluated in the current study was more complex. Then the hypothesis was tested that reducing salt concentration in the product with the higher dispersed phase volume would lead to no significant difference in perceived saltiness up to a certain level of salt reduction. Salt concentrations used in these studies were chosen to be within the range presently found in commercial soups.

\section{Results and discussion}

\section{Microstructure and viscosity}

Figure 1 shows optical micrographs of emulsions and vegetable soup samples containing $0.63 \mathrm{~g}$ salt $/ 100 \mathrm{~g}$; gelatinized pea starch granules are highlighted. Figure 2 shows the corresponding particle size distributions The $\mathrm{d}_{4,3}$ of the single emulsion was $23.7 \pm 0.5 \mu \mathrm{m}, 30.2 \pm 0.2 \mu \mathrm{m}$ for the duplex emulsion, $26.1 \pm 0.1 \mu \mathrm{m}$ for the single emulsion based vegetable soup and the duplex emulsion based vegetable soup had a $\mathrm{d}_{4,3}$ of $31.2 \pm 0.1 \mu \mathrm{m}$.

The micrographs of the emulsion samples (Figure 1a, 1c) show the typical microstructure of an unflocculated emulsion with a broad droplet size spectrum. The droplets of the duplex emulsion appear dark due to the 

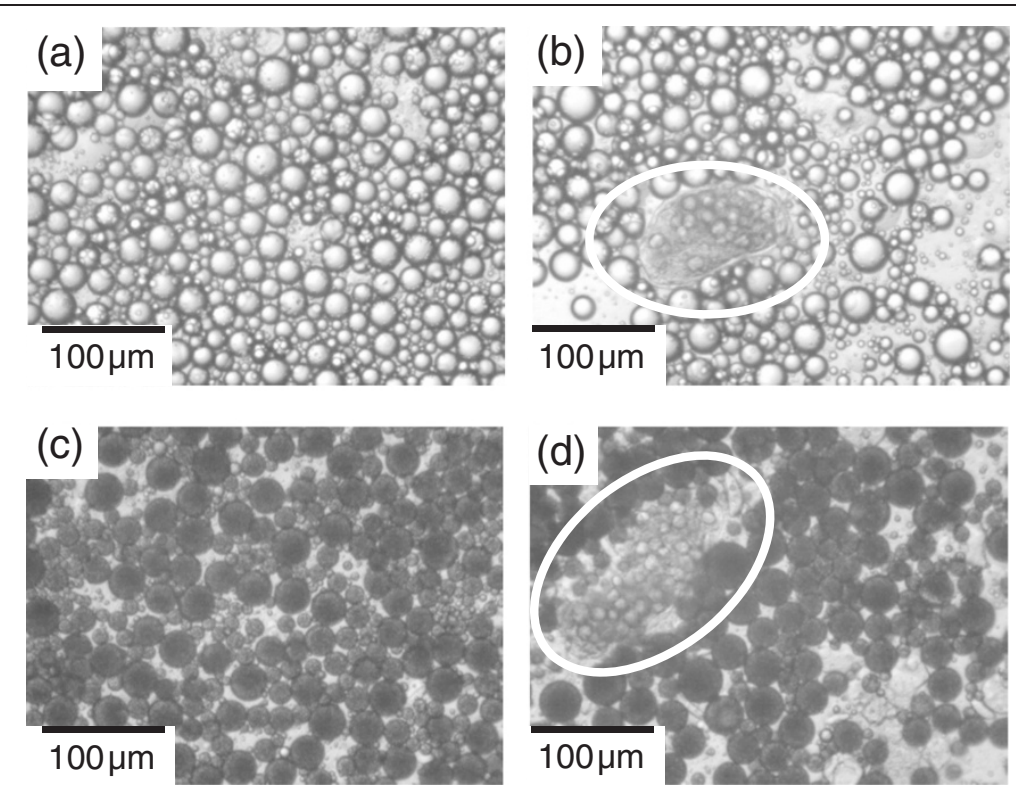

Figure 1 a) o/w, b) o/w based soup, c) w/o/w and d) w/o/w based soup.

enclosed water droplets corresponding to the droplet phase of the initially prepared w/o emulsion. The dark appearance of duplex emulsion droplets has previously been reported in the literature [32-34]. The droplet size spectra as well as the $d_{4,3}$ values of both types of emulsions compare well and, hence, droplet size can be removed as a variable which may influence saltiness perception.

Addition of pea purée to the emulsions to form a simple vegetable soup introduced an additional structure component as can clearly be seen in Figure $1 \mathrm{~b}, 1 \mathrm{~d}$ in which gelatinized pea starch granules have been highlighted. Their presence is also reflected as an additional peak in the particle size data (Figure 2), which was verified by sizing of the pea purée alone (results not shown).

Figure 3 shows the viscosity behavior of the four samples. Immediately obvious is the difference in viscosity between the single and the duplex systems for both emulsion and soup. The viscosity difference is much smaller comparing an emulsion and the corresponding soup. These observations are not surprising. Shear viscosity of an emulsion can be estimated with the KriegerDougherty equation [35]:

$$
\eta_{r}=\left[1-\frac{\phi}{\phi_{m}}\right]^{-2.5 \phi_{m}}
$$

with $\eta_{\mathrm{r}}=$ relative viscosity [1] defined as $\eta_{\mathrm{e}} / \eta_{\mathrm{c}}$ whereby $\eta_{\mathrm{e}}=$ emulsion viscosity $[\mathrm{Pa} s]$ and $\eta_{\mathrm{c}}=$ viscosity of continuous emulsion phase $\left[\begin{array}{ll}\mathrm{Pa} & \mathrm{s}\end{array}\right], \phi=$ dispersed volume fraction [1], $\phi_{\mathrm{m}}=$ maximum packing fraction [1]. The maximum packing fraction for polydisperse emulsions is between 0.65 and 0.8 (depending on packing structure). The dispersed volume fraction for the single emulsion containing $32.64 \mathrm{~g}$ oil/ $/ 100 \mathrm{~g}$ is 0.35 and it is 0.51 for the duplex emulsion (calculated with a density of $917 \mathrm{~kg} \cdot \mathrm{m}^{-3}$ for sunflower oil). Thus the viscosity of the duplex emulsion could be expected to be a factor of 2.4 to 3.5 higher than the viscosity of the single emulsion. Experimentally, a factor of 4 was found (viscosity at $10 \mathrm{~s}^{-1}: 6 \pm 1 \mathrm{mPa} \mathrm{s}$
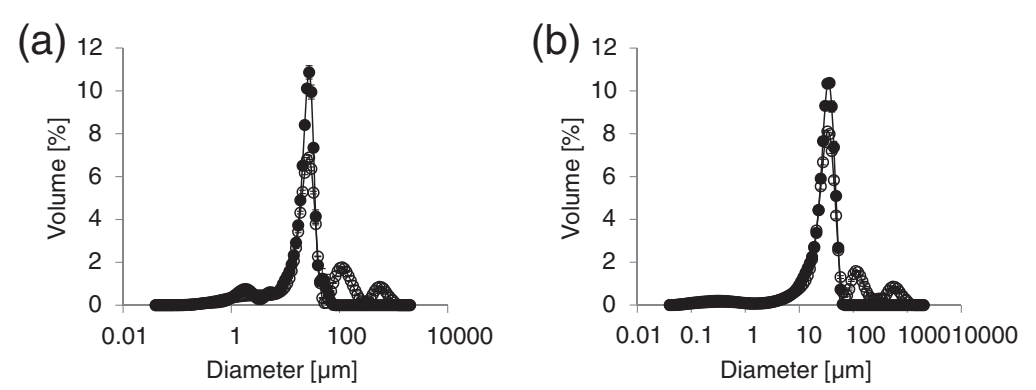

Figure 2 a) o/w and b) w/o/w systems. Filled symbols are for emulsions and open symbols for soups. 


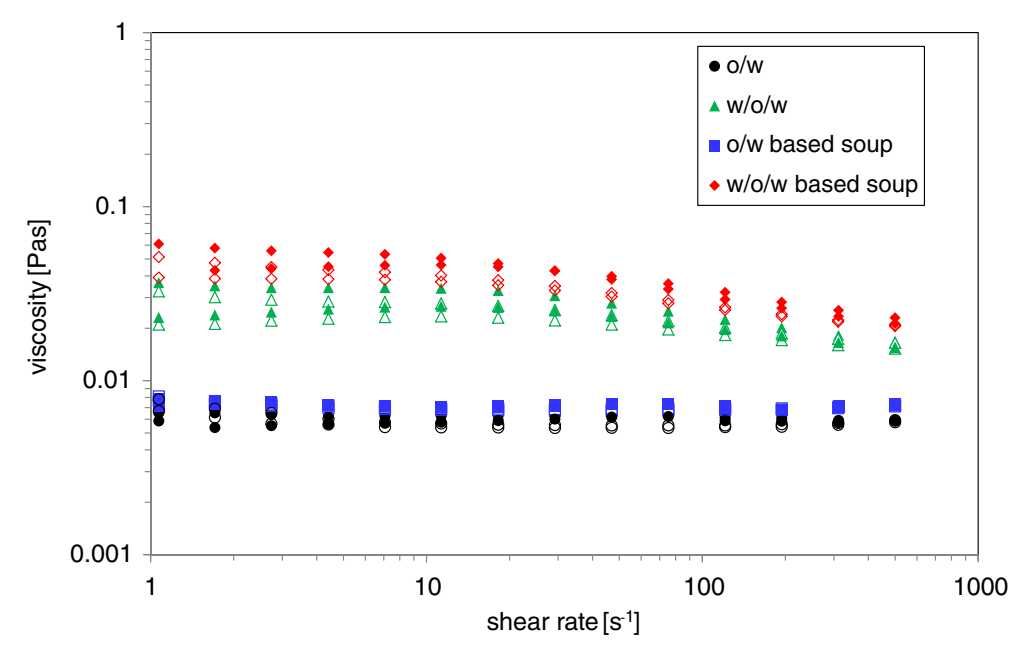

Figure 3 Viscosity profiles.

and $24 \pm 3 \mathrm{mPa}$ s for single and duplex emulsion respectively). Conducting the same analysis for the soup samples requires an estimate of the particulate dispersed phase volume added to the sample with the pea purée. Assuming a dispersed volume fraction increase by 0.1 returns a larger increase in viscosity for both types of samples than found experimentally. $7 \pm 1 \mathrm{mPa} s$ and $35 \pm 3 \mathrm{mPa} \mathrm{s}$ was the viscosity of the single emulsion based soup and the duplex emulsion based soup, respectively $\left(\right.$ at $10 \mathrm{~s}^{-1}$ ). However, the experimental values are not too different from the predicted values indicating that the Krieger-Dougherty equation is a useful tool to predict viscosity also for complex emulsions.

The increased viscosity of the duplex samples could be expected to affect saltiness perception. Previous studies have shown that viscosity increase leads to a decrease in saltiness perception [36-41]. On the other hand, it has also been demonstrated that including particles in a liquid food may enhance saltiness perception [42]. This is proposed to be due to the solid particles increasing mixing efficiency with saliva and thus salt delivery to the taste buds. Here the two higher viscous samples contain a larger volume fraction of dispersed particles which may promote in-mouth mixing.

\section{Saltiness perception}

Results of paired comparison tests, indicating which sample of each pair was perceived as the saltiest and calculated significance values, are included in Table 1 . In PC1, the two samples of water contained the same amount of salt as the samples of the other two pairs evaluated in this session. Results indicated assessors clearly identified the saltier sample in the water-based pair evaluated in PC1 $(P$-value $<0.0001)$. Thus, it can be assumed that a perceivable difference existed in the salt concentration between the two emulsion samples provided in PC2 if, indeed, the salt concentration of the continuous aqueous phase was the key driver of saltiness perception. However, as Table 1 shows, in PC2 results only indicated a trend for the duplex emulsion to be saltier than the single emulsion $(P=0.0595)$. Interestingly, sensory assessment of the same emulsions with the addition of $10 \mathrm{~g}$ pea purée showed that the duplex emulsion based soup was perceived to be significantly saltier than the single emulsion sample (PC3). This result seems to reinforce the trend found in PC2. Instrumental measurements indicated significant viscosity differences between the single and duplex emulsion and soup samples; indeed, several assessors commented that both duplex emulsion-based samples were thicker and creamier than the single. Thus, despite working with viscosity disparate samples, the result for the more complex sample pair (complex emulsion/soup-base) was as expected based on [26], indicating the aqueous phase tastant concentration is important in perception. It is possible that the higher dispersed phase volume enhanced mixing with saliva and thus accelerated transport of salt to the taste buds, as previously argued for liquid foods containing solid particles [42], or even that the higher salt concentration in the aqueous phase of the duplex emulsion created a sensory contrast effect greater than in the single emulsion. It is not likely that the present finding is a consequence of peas containing sodium and potassium known to impart saltiness [13-15]. Typical levels in fresh green peas are $6 \mathrm{mg} \mathrm{Na} / 100 \mathrm{~g}$ and $350 \mathrm{mg} \mathrm{K} / 100 \mathrm{~g}[43,44]$, which is very low compared to the amount of added salt in the studied samples.

PC4 and PC5 evaluated whether the overall salt content could be reduced in the duplex emulsion-based product without reducing perception of saltiness when compared to the single emulsion-based product. In PC4, the overall salt concentration of the duplex emulsion- 
Table 1 Sample pairs presented to assessors

\begin{tabular}{|c|c|c|c|c|c|}
\hline Test & Sample & $\begin{array}{l}\mathrm{g} \text { salt } / 100 \mathrm{~g} \\
\text { product }\end{array}$ & $\begin{array}{l}\text { Continuous } \\
\text { product phase salt } \\
\text { concentration } / \mathrm{mol} / \mathrm{L}\end{array}$ & $\begin{array}{l}\text { Number of assessors } \\
\text { judging this sample } \\
\text { to be the saltier } \\
\text { of the pair }\end{array}$ & $P$-value \\
\hline \multirow[t]{2}{*}{ PC1 } & Water & 0.94 & 0.160 & 4 & $<0.0001$ \\
\hline & Water & 1.21 & 0.207 & 37 & \\
\hline \multirow[t]{2}{*}{ PC2 } & $\mathrm{o} / \mathrm{W}$ & 0.63 & 0.160 & 14 & 0.0596 \\
\hline & $w / o / w$ & 0.63 & 0.207 & 27 & \\
\hline \multirow[t]{2}{*}{ PC3 } & o/w soup & 0.63 & 0.160 & 9 & 0.0004 \\
\hline & w/o/w soup & 0.63 & 0.207 & 32 & \\
\hline \multirow[t]{2}{*}{ PC4 } & o/w soup & 0.63 & 0.160 & 25 & 0.1081 \\
\hline & w/o/w soup & 0.57 & 0.187 & 14 & \\
\hline \multirow[t]{2}{*}{ PC5 } & o/w soup & 0.63 & 0.160 & 28 & 0.0095 \\
\hline & w/o/w soup & 0.50 & 0.166 & 11 & \\
\hline
\end{tabular}

based soup was reduced to $0.57 \mathrm{~g}$ salt $/ 100 \mathrm{~g}$ compared to $0.63 \mathrm{~g}$ salt $/ 100 \mathrm{~g}$ for the single emulsion. Paired comparison testing returned insufficient evidence to suggest a significant difference in saltiness between the two samples as shown in Table 1. However, there was a trend in the data pointing towards higher perceived saltiness of the sample in the pair that contained the overall higher salt concentration, which was the single emulsion/soup based product. Indeed, further analysis of the resultant data from PC4 for similarity testing (BS 5495:2007) indicated the sample pair cannot be concluded to be perceptually identical in terms of saltiness. Further salt reduction in the duplex emulsion/soup based product to $0.5 \mathrm{~g}$ salt $/ 100 \mathrm{~g}$ led to the single emulsion/soup product being perceived as significantly saltier (Table 1). Assessors commented again that the duplex samples were thicker and creamier than the single emulsion samples.

The results of the actual salt reduction tests conducted in this study are complex but to some degree confirm previous findings [26] that perception of saltiness is a complex function of salt concentration in the aqueous phase and aqueous phase volume. In the present study, the use of single and duplex emulsion systems led to comparison of samples which differed significantly in viscosity. As mentioned previously, studies have shown increasing viscosity commonly decreases tastant perception [36-41], and this may result in a reduced perception of saltiness in duplex emulsions compared to single emulsions irrespective of salt content. It appears that the disparity in viscosity is not "overcome" by the increased dispersed phase volume in the duplex emulsion promoting in-mouth mixing and acceleration of tastant transport to the taste buds. However, this observation depends on the difference in salt content. Thus, to further clarify use of duplex microstructure in salt reduction technology, control of product viscosity and product microstructure would be key to understanding the primary cause of altered taste perception. On the other hand, reducing the fat content of the type of emulsion-based product tested by incorporating water into the droplets of the dispersed phase appeared to have no effect on saltiness perception other than increasing the dispersed phase volume of the emulsion. The study of the viscosity behavior of duplex emulsions has received little attention compared to single emulsions [45], and it cannot be excluded that the included water droplets affect the viscosity behavior of the duplex system.

\section{Conclusions}

This study aimed to provide initial evaluation to assess whether duplex emulsion technology presents an opportunity to reduce salt in emulsion-based liquid or semiliquid foods while keeping the fat content constant. Emulsions and a more complex emulsion-based ambient vegetable soup were tested using paired comparison tests to identify the sample perceived as overall saltier of each pair. The results showed that salt reduction may be possible despite the added technology increasing the overall measured viscosity of the product. The changes in viscosity behavior impact mouthfeel, which may be exploitable in addition to the contribution towards salt reduction.

To conclude, in view to applying this technology to real processed foods, it needs to be tested for the product in question, but given the interesting novel data presented it should be considered as part of a salt reduction tool box.

\section{Methods}

All materials used to prepare the emulsions were of food grade quality and used as obtained. Sunflower oil was purchased from a local supermarket, pea protein isolate (PPI) from Myprotein (Manchester, UK), sodium chloride 
(+99\%) from Sigma-Aldrich (Gillingham, UK), potassium chloride (+99\%) from Fisher Scientific (Loughborough, UK) and polyglycerol polyricinoleate (Crestamul PR) from AAK Bakery Services (Oldham, UK). The vegetable base was prepared from frozen peas purchased in a local supermarket and bottled water (Evian, Danone, France) was used to prepare the foods.

Emulsions were formed so that the fat content remained constant and comminution conditions were selected to obtain comparable droplet size distributions in single and double emulsions with a mean diameter of 25 to $35 \mu \mathrm{m}$. Emulsion interfaces with oil on the inside were stabilized with protein. The internal interface of the w/o/w duplex emulsions was stabilized with polyglycerol polyricinoleate (PGPR). To minimize microstructure instability through diffusion of the internal water phase into the external water phase due to osmotic pressure gradients, potassium chloride was added to the internal water phase. However, "emptying out" was still observed when the samples were kept for longer than one week, probably due to differences in chemical potential between the two aqueous phases as recently demonstrated [32].

Emulsions and vegetable soup were prepared and analyzed as detailed in the following sections. Preparation and analysis were within the space of $48 \mathrm{~h}$.

\section{Single emulsions}

A total of $100 \mathrm{~g}$ of single emulsion contained $1 \mathrm{~g}$ of PPI, $66.36 \mathrm{~g}$ of aqueous $\mathrm{NaCl}$ solution and $32.64 \mathrm{~g}$ of sunflower oil. The molar concentration of the $\mathrm{NaCl}$ solution was chosen to obtain the desired salt concentration in the final sample. Batches of emulsion (100 g) were prepared by immersing a high shear overhead mixer (L5M, emulsor screen, Silverson, Chesham, UK) into a glass beaker containing the aqueous emulsion phase, initially mixing for one minute at 3,000 rpm during which the oil phase was added followed by shearing for four minutes at 4,000 rpm. Temperature was not controlled.

\section{Duplex emulsions}

Duplex emulsions of the w/o/w type were formed in two stages by initially preparing a w/o emulsion with $30 \mathrm{~g}$ $0.2 \mathrm{M}$ aqueous $\mathrm{KCl}$ solution/100 g. The oil phase contained $2.86 \mathrm{~g}$ PGPR/100 g. One hundred-gram batches of this w/o emulsion were formed by adding both phases to a glass beaker followed by mixing at 7,000 rpm for two minutes. The duplex emulsion was then obtained by emulsifying $48 \mathrm{~g}$ w/o emulsion into $52 \mathrm{~g}$ aqueous phase containing $1 \mathrm{~g} / 100 \mathrm{~g} \mathrm{PPI}$ and $\mathrm{NaCl}$ at the level required to obtain the desired salt concentration in the final sample. The comminution conditions were the same as in the single emulsion.

\section{Vegetable soup}

Vegetable soups were formulated based on emulsion ingredient and pea puree prepared as described earlier. One hundred grams of soup contained $90 \mathrm{~g}$ emulsion (single or duplex) and $10 \mathrm{~g}$ pea purée. The two ingredients were mixed manually and it was verified that emulsion microstructure remained intact by assessing the samples microscopically. Pea purée was prepared by initially washing thawed peas with water followed by microwave cooking ( $800 \mathrm{~W}, 8$ minutes) of $200 \mathrm{~g}$ peas in excess water. Once cooked, the water content was adjusted to $25 \mathrm{~g}$ water/100 g peas by draining the cooking water and adding fresh water. This composition was then blended using a hand blender until a smooth mixture was obtained, which was then passed through a sieve with fine holes.

\section{Light microscopy}

The microstructure of the samples was evaluated using a light microscope (Leitz Diaplan, Stuttgart, Germany) applying bright field illumination. Micrographs were taken with a digital camera (Pixalink PLA662, Ottawa, ON, Canada).

\section{Particle size}

Particle size analysis was carried out with a laser diffraction particle size analyzer (Beckman Coulter LS 13230, Miami, FL, USA). All samples were measured in aqueous dispersion and measurement data were analyzed based on the Fraunhofer model using the instrument's software. Measurements were performed in triplicate and results are shown as volume based density distribution as well as average volume weighted mean diameter $d_{4,3}$.

\section{Emulsion viscosity}

Emulsion viscosity was measured in steady shear with a rotational rheometer (MCR301, Anton Paar, Graz, A) fitted with concentric cylinder geometry $(\mathrm{C} 27)$ at $20^{\circ} \mathrm{C}$. Shear rate was stepwise increased from 1 to $500 \mathrm{~s}^{-1}$ and then decreased to $1 \mathrm{~s}^{-1}$. Samples were analyzed in duplicate and both data traces are shown in the Results section. Viscosity values in the Results section are reported as averaged data acquired at $10 \mathrm{~s}^{-1}$ on the increasing and decreasing shear rate ramp.

\section{Sensory evaluation}

Sensory assessment of the products was performed using simple paired comparison tests (2-Alternate Forced Choice tests, BS ISO 5495:2007) requiring assessors to determine which of two samples was perceived as saltier. In a first series of paired comparison tests (Table 1), samples (water-based, emulsion-based and complex emulsion/soup-based) with constant salt concentration in the continuous product phase were evaluated. In a 
second series of paired comparison tests, the overall concentration of salt in the duplex emulsion product was reduced and compared to the single emulsion product (complex emulsion/soup-base). Here, the samples of each pair had a different overall salt content and the concentration in the continuous product phase was increasingly similar. Assessors were recruited by advertisement (soup usage was not a prerequisite), from the students and staff of the University of Nottingham. A total of 41 assessors attended the first session which consisted of tests PC1, PC2 and PC3, and 39 assessors attended the second session of tests PC4 and PC5 (Table 1). Each sample pair was assessed once by each assessor. Sensory evaluation of samples was conducted approximately $24 \mathrm{~h}$ after sample preparation. For each pair, samples of $15 \mathrm{~mL}$ were presented in a randomized, balanced order across the panel, in plastic containers labeled with a random three-digit code. The order of the three tests was also randomized across the panel.

All testing was carried out in a quiet, air-conditioned room $\left(18^{\circ} \mathrm{C}\right)$ and in individual booths with northern hemisphere lighting. A full explanation of the test was provided prior to testing. Assessors were told they would be given a series of pairs of samples. For each pair, assessors were instructed to taste the samples in the order presented and to determine which sample was the highest in "overall saltiness". "No difference" answers were not allowed. Assessors were informed that other attributes, such as texture, may differ between the samples and they were asked to focus only on the overall saltiness perceived. In addition, space was provided on the test form to give any comments about the samples they wished. Assessors were instructed to cleanse their palate before and between samples with unsalted crackers (99\% Fat Free, Rakusen's, Leeds, UK) and mineral water (Evian).

Data were acquired and results were analyzed as individual two-tailed paired tests $(P<0.05)$ using Fizz software (Biosystèmes, Couternon, France).

\section{Ethics approval}

This study was approved by the Ethics Committee in the Medical School of The University of Nottingham.

\section{Abbreviations \\ 2AFC: Sensory assessment of saltiness of emulsion pairs; PGPR: Polyglycerol polyricinoleate; WHO: World Health Organization.}

\section{Competing interests}

The authors declare that they have no competing interests.

\section{Acknowledgments}

The authors wish to thank the UK Technology Strategy Board for funding this project (TP/6/DAM/6/S/K3004C), the panelists for attending the sessions and the TSB project team, Joanne Hort and Cécile Morris for discussion.

\section{Author details}

${ }^{1}$ Food Sciences, Sutton Bonington Campus, The University of Nottingham, Loughborough LE12 5RD, UK. ${ }^{2}$ Riddet Institute, Massey University, Private Bag 11222, Palmerston North, New Zealand.

\section{Authors' contributions}

$M L$ conceived the idea for the study, formulated the products and prepared the first draft of the manuscript. LH designed, supervised and analyzed the sensory evaluation of the products. ML conducted the droplet size and viscosity measurements, which were analyzed by BW. LH and BW developed the first draft manuscript into the final version suitable for publication. All authors read and approved the final manuscript.

Received: 3 January 2012 Accepted: 13 April 2012

Published: 18 July 2012

\section{References}

1. Kremer S, Mojet J, Shimojo R: Salt reduction in foods using naturally brewed soy sauce. J Food Sci 2009, 74:S255-S262.

2. Brown IJ, Tzoulaki I, Candeias V, Elliott P: Salt intakes around the world: implications for public health. Int J Epidemiol 2009, 38:791-813.

3. WHO: Reducing salt intake in populations. Report of a WHO forum and technical meeting. Geneva: WHO Document Production Services.: World Health Organization; 2007.

4. He FJ, MacGregor GA: A comprehensive review on salt and health and current experience of worldwide salt reduction programmes. $J$ Hum Hypertens 2009, 23:363-384.

5. Mohan S, Campbell NRC: Salt and high blood pressure. Clin Sci 2009, 117:1-11.

6. Weinsier RL: Overview - salt and development of essential hypertension. Preventive Med 1976, 5:7-14.

7. He J, Ogden LG, Bazzano LA, Vupputuri S, Loria C, Whelton PK: Dietary sodium intake and incidence of congestive heart failure in overweight US men and women - First National Health and Nutrition Examination Survey Epidemiologic Follow-up Study. Arch Intern Med 2002, 162:1619-1624.

8. Cianciaruso B, Bellizzi V, Minutolo R, Tavera A, Capuano A, Conte G, De Nicola L: Salt intake and renal outcome in patients with progressive renal disease. MinerElectrolyte Metab 1998, 24:296-301.

9. Cappuccio FP, Kalaitzidis R, Duneclift S, Eastwood JB: Unravelling the links between calcium excretion, salt intake, hypertension, kidney stones and bone metabolism. J Nephrol 2000, 13:169-177.

10. James WP, Ralph A, Sanchez-Castillo CP: The dominance of salt in manufactured foods in the sodium-intake of affluent societies. Lancet 1987, 1:426-429.

11. Dotsch M, Busch J, Batenburg M, Liem G, Tareilus E, Mueller R, Meijer G: strategies to reduce sodium consumption: a food industry perspective. Crit RevFood Sci Nutr 2009, 49:841-851.

12. Girgis S, Neal B, Prescott J, Prendergast J, Dumbrell S, Turner C, Woodward $\mathrm{M}$ : A one-quarter reduction in the salt content of bread can be made without detection. Eur J Clin Nutr 2003, 57:616-620.

13. Frank RL, Mickelsen O: Sodium-potassium chloride mixtures as table salt. Am J Clin Nutr 1969, 22:464-470.

14. Vanderklaauw NJ, Smith DV: Taste quality profiles for 15 organic and inorganic salts. Physiol Behav 1995, 58:295-306.

15. McGregor R: Taste modification in the biotech era. Food Technol 2004, 58:24-30.

16. Breslin PAS, Beauchamp GK: Salt enhances flavour by suppressing bitterness. Nature 1997, 387:563-563.

17. Beauchamp GK: Salt preference in humans. In Encylopedia of Human Biology. Edited by Dulbecco R. San Diego: Academic; 1997:669-675.

18. Prescott J: Taste hedonics and the role of umami. Food Australia 2001, 53:550-554.

19. Roininen $K$, Lahteenmaki $L$, Tuorila H: Effect of umami taste on pleasantness of low-salt soups during repeated testing. Physiol Behav 1996, 60:953-958.

20. Morris C, Labarre C, Koliandris AL, Hewson L, Wolf B, Taylor AJ, Hort J: Effect of pulsed delivery and bouillon base on saltiness and bitterness perceptions of salt delivery profiles partially substituted with $\mathrm{KCl}$. Food QualPrefer 2010, 21:489-494. 
21. Angus F, Phelps T, Clegg S, Narein C, Ridder Den C, Kilcast D: Salt in processed foods. Leatherhead, UK: Leatherhead Food International; 2005. N0 00193.

22. Guerrero A, Kwon SS-Y, Vadehra DV: Salt enhanced foods. Societe des Products Nestle 1995, (Nestle SdP EP 0677249.

23. Lawrence G, Salles C, Palicki O, Septier C, Busch J, Thomas-Danguin T: Using cross-modal interactions to counterbalance salt reduction in solid foods. Int Dairy J 2011, 21:103-110.

24. Lawrence G, Salles C, Septier C, Busch J, Thomas-Danguin T: Odour-taste interactions: a way to enhance saltiness in low-salt content solutions. Food Qual Pref 2009, 20:241-248.

25. Yamamoto $Y$, Nakabayashi M: Enhancing effect of an oil phase on the sensory intensity of salt taste of $\mathrm{NaCl}$ in oil/water emulsions. J Texture Stud 1999, 30:581-590.

26. Malone ME, Appelqvist IAM, Norton IT: Oral behaviour of food hydrocolloids and emulsions. Part 2. Taste and aroma release. Food Hydrocolloid 2003, 17:775-784.

27. Goh SM, Leroux B, Groeneschild CAG, Busch J: On the effect of tastant excluded fillers on sweetness and saltiness of a model food. $J$ Food Sci 2010, 75:S245-S249.

28. Noort MWJ, Bult JHF, Stieger M, Hamer RJ: Saltiness enhancement in bread by inhomogeneous spatial distribution of sodium chloride. J Cereal Sci 2010, 52:378-386.

29. Burseg KMM, Brattinga C, de Kok PMT, Bult JHF: Sweet taste enhancement through pulsatile stimulation depends on pulsation period not on conscious pulse perception. Physiol Behav 2010, 100:327-331.

30. Busch J, Tournier C, Knoop JE, Kooyman G, Smit G: Temporal contrast of salt delivery in mouth increases salt perception. Chem Senses 2009, 34:341-348

31. Morris C, Koliandris AL, Wolf B, Hort J, Taylor A: Effect of pulsed or continuous delivery of salt on sensory perception over short time intervals. Chemosens Percept 2009, 2:1-8.

32. Pawlik A, Cox PW, Norton IT: Food grade duplex emulsions designed and stabilised with different osmotic pressures. J Colloid Interface Sci 2010, 352:59-67.

33. Garti N, Aserin A, Cohen Y: Mechanistic considerations on the release of electrolytes from multiple emulsions stablized by BSA and nonionic surfactants. J Controlled Release 1994, 29:41-51.

34. Rojas EC, Staton JA, John VT, Papadopoulos KD: Temperature-induced protein release from water-in-oil-in-water double emulsions. Langmuir 2008, 24:7154-7160.

35. Krieger IM, Dougherty TJ: A mechamism for non-Newtonian flow in suspensions of rigid spheres. Trans Soc Rheol 1959,

3:137-152.

36. Baines ZV, Morris ER: Flavour/taste perception in thickened systems: the effect of guar gum above and below c. Food Hydrocolloid 1987, 1:197-205.

37. Christensen CM: Effects of solution viscosity on perceived saltiness and sweetness. PerceptPsychophys 1980, 28:347-353.

38. Cook DJ, Hollowood TA, Linforth RST, Taylor AJ: Perception of taste intensity in solutions of random-coil polysaccharides above and below c. Food Qual Pref 2002, 13:473-480.

39. Moskowitz HR, Arabie P: Taste intensity as a function of stimulus concentration and solvent viscosity. J Texture Stud 1970, 1:502-510.

40. Pangborn RM, Traube IM: Effect of hydrocolloids on oral viscosity and basic taste intensities. J Texture Stud 1973, 4:224-241.

41. Koliandris AL, Morris C, Hewson L, Hort J, Taylor AJ, Wolf B: Correlation between saltiness perception and shear flow behaviour for viscous solutions. Food Hydrocolloid 2010 24:792-799.

42. Ferry AL, Hort J, Mitchell JR, Cook DJ, Lagarrigue S, Pamies BV: Viscosity and flavour perception: Why is starch different from hydrocolloids? Food Hydrocolloid 2006, 20:855-862.

43. Duke JA: Handbook of Legumes of World Economic Importance. New York: Plenum Press; 1981

44. Hulse $\mathrm{JH}$ : Nature, composition and utilization of food legumes. In Expanding the Production and Use of Cool Season Food Legumes. Edited by
Muehlbauer FJ, Kaiser WJ. Dordrecht: Kluwer Academic Publisher; 1994:77-97.

45. Pal R: Rheology of simple and multiple emulsions. Curr OpinColloid Interface Sci 2011, 16:41-60.

doi:10.1186/2044-7248-1-13

Cite this article as: Lad et al:: Enhancing saltiness in emulsion based foods. Flavour 2012 1:13.

\section{Submit your next manuscript to BioMed Central and take full advantage of:}

- Convenient online submission

- Thorough peer review

- No space constraints or color figure charges

- Immediate publication on acceptance

- Inclusion in PubMed, CAS, Scopus and Google Scholar

- Research which is freely available for redistribution 